Vol 12, Issue 6, 2019

Online - 2455-3891

Print - 0974-2441

$\underline{\text { Research Article }}$

\title{
FORMULATION AND EVALUATION OF DOLUTEGRAVIR SODIUM SOLID DISPERSIONS AND FAST DISSOLVING TABLETS USING POLOXAMER-188 AND JACK FRUIT SEED STARCH AS EXCIPIENTS
}

\author{
SUNDEEP MUPPARAJU, VIDYADHARA SURYADEVARA*, SAILAJA YALLAM, SANDEEP DOPPALAPUDI, SASIDHAR \\ REDDYVALLAM LC, RAMU ANNE
}

Department of Pharmaceutics, Chebrolu Hanumaiah Institute of Pharmaceutical Sciences, Chandramoulipuram, Guntur, Andhra Pradesh, India. Email: svidyadhara@gmail.com

Received: 05 March 2019, Revised and Accepted: 27 April 2019

\section{ABSTRACT}

Objective: The current work mainly focuses on solubility enhancement of dolutegravir which is a biopharmaceutical classification system Class-II drug using jack fruit seed starch (JFS2) as excipient which improves the drug release.

Materials and Methods: Starches were extracted using aqueous and alkali methods (sodium hydroxide at $0.1 \%, 0.25 \%$, and $0.5 \%$ concentrations) from jack fruit seed powder. These starches were evaluated for phytochemical and physicochemical parameters. Fast dissolving tablets were prepared using dolutegravir sodium solid dispersion, JFS2, and croscarmellose sodium (CCS) in various concentrations using wet granulation technique. Various pre- and post-compression parameters were evaluated along with in vitro drug release studies; characterization studies such as Fourier transform infrared (FTIR) spectroscopy, differential scanning calorimetry (DSC), scanning electron microscopy, X-ray diffraction (XRD), and stability studies.

Results: Phytochemical tests revealed the presence of only starch in all extracts. Starch prepared from $0.1 \%$ sodium hydroxide (JFS2) showed best physicochemical properties. From in vitro dissolution studies, it was observed that solid dispersion formulation DF3 containing dolutegravir sodium and poloxamer-188 in 1:1.5 ratios showed a better dissolution rate. From in vitro dissolution studies, tablet formulations DFT6 and DFT9 containing $12.5 \% \mathrm{w} / \mathrm{w}$ of JFS2 and $12.5 \% \mathrm{w} / \mathrm{w}$ of CCS showed enhanced dissolution rate compared with other formulations. FTIR and DSC studies revealed that there were no major interactions between drug and excipients. XRD studies revealed the nature of formulations. Accelerated stability studies showed that all tablets were stable.

Conclusion: The tablets prepared using jack fruit starch seed starch revealed the superdisintegrant property of starch.

Keywords: Jack fruit seed starch, Dolutegravir, Poloxamer-188, Solid dispersions, Fast dissolving tablets.

(C) 2019 The Authors. Published by Innovare Academic Sciences Pvt Ltd. This is an open access article under the CC BY license (http://creativecommons. org/licenses/by/4. 0/) DOI: http://dx.doi.org/10.22159/ajpcr.2019.v12i6.33302

\section{INTRODUCTION}

Solubility is an important physicochemical factor affecting the absorption of the drug and its therapeutic effectiveness. Nowadays, scientists are focusing on the development of oral dosage forms of poor aqueous solubility drugs through various solubility enhancing approaches. Among these approaches, preparation of solid dispersions is one of the widely used approaches. The term solid dispersion refers to a group of solid products consisting of at least two different components, a hydrophilic matrix and a hydrophobic drug $[1,2]$.

The presentstudy is aimed to develop dolutegravir sodium fast dissolving tablets using solid dispersion technique to improve the solubility and dissolution rate. Dolutegravir sodium is an antiretroviral agent which mainly acts by inhibiting the enzyme human immunodeficiency virus integrase which is needed for the viral replication process. According to the Biopharmaceutical Classification Scheme, dolutegravir can be considered as Class II drug, i.e., water-insoluble, lipophilic, and highly permeable compound. Therefore, it is possible to improve its bioavailability by increasing apparent solubility in water through solid dispersion technology [3-5]. Fast dissolving tablet is a solid dosage form containing a medicinal substance or active ingredient which disintegrates rapidly usually within a matter of seconds when placed on the tongue. It helps in faster drug release and better effect of formulation. Although several synthetic carriers have been developed, natural carrier development is gaining focus in recent days due to their easy availability [6].
A novel solid dispersion formulation of dolutegravir sodium was prepared by fusion method using poloxamer 188 as a carrier. Dolutegravir sodium tablets were prepared by wet granulation method with the best solid dispersion along with jack fruit seed starch (JFS2), employing a neoteric method which could prove the superdisintegrant property of JFS2.

\section{MATERIALS AND METHODS}

Procurement of materials

Dolutegravir sodium was a gift sample from Dr. Reddy's Lab (Hyderabad, India). Poloxamer 188 was a gift sample from Pellets Pharma Ltd. (Hyderabad, India). Sodium hydroxide, magnesium stearate, and talc were procured form S. D Fine Chem. Ltd. (Mumbai, India). Croscarmellose sodium (CCS) was a gift sample from NATCO Pharma Ltd. (Hyderabad, India) and jackfruit seeds were procured from the local market (Guntur, Andhra Pradesh, India).

\section{Extraction of jackfruit seed starch using alkali method}

JFS2 was isolated using aqueous and alkali extraction methods [7]. Jack fruit seed flour ( $5 \mathrm{gm}$ ) was added in water, $0.1 \%, 0.25 \%$, and $0.5 \%$ of sodium hydroxide $(100 \mathrm{ml})$ and soaked $(6 \mathrm{~h}$ or $8 \mathrm{~h}$ ) at room temperature with occasional stirring. The slurry was filtered through 120 mesh stainless sieve. The filtrate solution was kept in a refrigerator for overnight and then removed, and the supernatant was discarded. The crude starch was washed with distilled water for 3 times, and the starch cake was dried at $40^{\circ} \mathrm{C}$ for $24 \mathrm{~h}$ in tray dryer. The starch was grounded 
into a fine powder using mortar and pestle. The obtained starches were packed in a plastic bag and kept at room temperature until further use.

\section{Phytochemical tests for jack fruit seed powder and extracted} starches

The raw jackfruit powder and starch extracts were subjected to phytochemical tests for the identification of carbohydrates, proteins, alkaloids, glycosides, and steroids by various tests [8]. The results are given in Table 1.

Evaluation of physicochemical properties of jack fruit seed powder and extracted starch

Various physicochemical properties such as gelatinization temperature, $\mathrm{pH}$, viscosity, swelling index, and water absorption index were evaluated using suitable methods [9]. All the results are indicated in Table 2.

\section{Total microbial load of isolated JFS2}

The total microbial load is an important parameter which decides the suitability of a substance for use as an excipient in the pharmaceutical dosage form. The agar medium was prepared and placed in an autoclave for $1 \mathrm{~h}$. To this, bacterial culture like Escherichia coli was added, mixed well and poured into Petri plates and allowed to solidify for $10 \mathrm{~min}$. After solidification, the starch powder was sprinkled and kept in an incubator for $24 \mathrm{~h}$. According to many pharmacopeias, in case of excipients from natural origin, the total aerobic count should not be $>1000 \mathrm{cfu} / \mathrm{g}$ and total fungal count should not exceed $100 \mathrm{cfu} / \mathrm{g}$.

\section{Acidity}

About $1 \mathrm{~g}$ of starch was added to $100 \mathrm{ml}$ of ethanol (70\%) which was previously neutralized to phenolphthalein solution. This solution was shaken for $1 \mathrm{~h}$, filtered and $50 \mathrm{ml}$ of the filtrate was titrated with $0.1 \mathrm{M}$ sodium hydroxide.

Table 1: Phytochemical tests for JFSP and extracted starches

\begin{tabular}{llllll}
\hline Test & JFSP & JFS1 & JFS2 & JFS3 & JFS4 \\
\hline Carbohydrates & + & + & + & + & + \\
Polysaccharides & + & + & + & + & + \\
Proteins & - & - & - & - & - \\
Alkaloids & + & - & - & - & - \\
Glycosides & - & - & - & - & - \\
Steroids & + & - & - & - & - \\
Flavonoids & + & - & - & - & - \\
Saponins & + & - & - & - & - \\
\hline
\end{tabular}

+ve indicates positive and-ve indicates negative. JFSP: Jack fruit seed powder, JFS1: Jack fruit seed powder extracted with water, JFS2: Jack fruit seed powder extracted with $0.1 \%$ sodium hydroxide, JFS3: Jack fruit seed powder extracted with $0.25 \%$ sodium hydroxide, JFS4: Jack fruit seed powder extracted with

$0.5 \%$ sodium hydroxide

\section{Fluorescence}

About 500 mg of starch powder was dissolved in an organic solvent and placed on a glass slide. The slide was examined under ultraviolet (UV) cabinet for the presence of any fluorescent material.

\section{Oxidizing substances}

To $5.0 \mathrm{~g}$ of sample, $10 \mathrm{ml}$ of water and $1 \mathrm{ml}$ of acetic acid were added and stirred until a homogeneous suspension was obtained. $0.5 \mathrm{ml}$ of a freshly prepared saturated solution of potassium iodide was added, mixed and allowed to stand for $5 \mathrm{~min}$

\section{Sulfated ash}

About 1-2 g of the starch was placed in an accurately weighed crucible and ignited until thoroughly charred. Then, it is cooled and the residue was moistened with $1 \mathrm{ml}$ of sulfuric acid. It was heated gently until white fumes are no longer evolved and ignited at $800^{\circ} \mathrm{C}$ until black particles have disappeared. The crucible was cooled and few drops of sulfuric acid were added and heated. Then, it was weighed. This procedure was repeated until two successive weighing does not differ by $>0.5 \mathrm{mg}$.

\section{Loss on drying}

Loss on drying is widely used to determine the moisture content of a sample, although occasionally it may refer to the loss of any volatile matter from the sample. Not $>15 \%$ (for all starches except potato starch) and not $>20 \%$ (for potato starch) of weight loss should be obtained. It was determined by drying $0.2 \mathrm{~g}$ of starch in an oven at $105^{\circ} \mathrm{C}$.

\section{Test for amylose content}

About $100 \mathrm{mg}$ of isolated starch sample was taken, and to it, $1 \mathrm{ml}$ of ethanol and $9 \mathrm{ml}$ of $1 \mathrm{~N}$ sodium hydroxide were added and kept aside for overnight. The suspension was thoroughly mixed. The dispersed sample was transferred to a $100 \mathrm{ml}$ volumetric flask and diluted to the mark with distilled water. $5 \mathrm{ml}$ of test starch solution was pipetted into a $100 \mathrm{ml}$ volumetric flask and $1 \mathrm{ml}$ of $1 \mathrm{~N}$ glacial acetic acid and $2 \mathrm{ml}$ of iodine solution $(0.02 \mathrm{~N}$ ) were added. The volume was made up to $100 \mathrm{ml}$ with distilled water and the absorbance was measured at $620 \mathrm{~nm}$.

Preparation of dolutegravir sodium solid dispersions by fusion method

Solid dispersions of dolutegravir sodium were prepared using Poloxamer-188 in different ratios by fusion method. Poloxamer-188 was placed in a China dish and heated at $40^{\circ} \mathrm{C}$ until it gets melted, and then dolutegravir sodium was added to it. After vigorous stirring in normal temperature, the mixture gets solidified. The solid mass was crushed, pulverized, and sieved. The granules obtained were stored in a desiccator for further studies. The results are given in Table 3.

Table 2: Evaluation of physicochemical properties for jack fruit seed powder and extracted starches

\begin{tabular}{|c|c|c|c|c|c|}
\hline Parameters & JFSP & JFS1 & JFS2 & JFS3 & JFS4 \\
\hline Gelatinization temperature & $218-221^{\circ} \mathrm{C}$ & $220-223^{\circ} \mathrm{C}$ & $210-215^{\circ} \mathrm{C}$ & $224-227^{\circ} \mathrm{C}$ & $226-229^{\circ} \mathrm{C}$ \\
\hline $\mathrm{pH}$ & 6.32 & 6.50 & 7.10 & 6.78 & 6.98 \\
\hline Viscosity & $1.856 \mathrm{cps}$ & $2.089 \mathrm{cps}$ & $2.578 \mathrm{cps}$ & $2.265 \mathrm{cps}$ & $2.312 \mathrm{cps}$ \\
\hline Swelling index & 58 & 63 & 83 & 76 & 78 \\
\hline Water absorption index & 250 & 270 & 290 & 260 & 280 \\
\hline Microbial growth & Absent & Absent & Absent & Absent & Absent \\
\hline Loss on drying (\%) & 9.0 & 9.2 & 8.0 & 8.5 & 8.8 \\
\hline Fluorescence & $\begin{array}{l}\text { No fluorescence } \\
\text { observed }\end{array}$ & $\begin{array}{l}\text { No fluorescence } \\
\text { observed }\end{array}$ & $\begin{array}{l}\text { No fluorescence } \\
\text { observed }\end{array}$ & $\begin{array}{l}\text { No fluorescence } \\
\text { observed }\end{array}$ & $\begin{array}{l}\text { No fluorescence } \\
\text { observed }\end{array}$ \\
\hline Acidity & Non acidified & Non acidified & Non acidified & Non acidified & Non acidified \\
\hline Sulphated ash & $0.09 \%$ & $0.08 \%$ & $0.1 \%$ & $0.2 \%$ & $0.1 \%$ \\
\hline Amylose content & 16.36 & 14.28 & 20.25 & 18.36 & 17.69 \\
\hline
\end{tabular}

JFSP: Jack fruit seed powder, JFS1: Jack fruit seed powder extracted with water, JFS2: Jack fruit seed powder extracted with 0.1\% sodium hydroxide, JFS3: Jack fruit seed powder extracted with $0.25 \%$ sodium hydroxide, JFS4: Jack fruit seed powder extracted with $0.5 \%$ sodium hydroxide 
Evaluation of pre-formulation parameters

The prepared solid dispersions were evaluated for various preformulation parameters such as angle of repose, Carr's index, Hausner's ratio, and particle size $[10,11]$. The results are indicated in Table 4.

\section{Drug content uniformity for solid dispersions}

Solid dispersions of dolutegravir sodium equivalent to $50 \mathrm{mg}$ was weighed and transferred into a $100 \mathrm{ml}$ volumetric flask. To this, a small quantity of methanol was added to dissolve. It was shaken occasionally for about $15 \mathrm{~min}$, and the volume was made up to $100 \mathrm{ml}$ by methanol. The solution was filtered using Whatman filter paper. The filtrate was subsequently diluted with $6.8 \mathrm{pH}$ phosphate buffer, and the absorbance was measured at $258 \mathrm{~nm}$ using $6.8 \mathrm{pH}$ phosphate buffer as blank.

Table 3: Composition of dolutegravir sodium solid dispersions prepared by fusion method

\begin{tabular}{ll}
\hline Composition & $\begin{array}{l}\text { Drug: Polymer ratio (Dolutegravir } \\
\text { sodium*: Poloxamer-188) }\end{array}$ \\
\hline DF1 & $1: 0.5$ \\
DF2 & $1: 1.0$ \\
DF3 & $1: 1.5$ \\
DF4 & $1: 2.0$ \\
DF5 & $1: 3.0$ \\
DF6 & $1: 4.0$ \\
\hline
\end{tabular}

*One part is equal to $50 \mathrm{mg}$
In vitro dissolution studies

Dissolution studies for all solid dispersions were performed in a calibrated eight station dissolution test apparatus (LABINDIA DS8000) equipped with paddles employing $900 \mathrm{ml}$ of $6.8 \mathrm{pH}$ phosphate buffer as a dissolution medium. The paddles were operated at $50 \mathrm{rpm}$, and the temperature was maintained at $37 \pm 1^{\circ} \mathrm{C}$ throughout the experiment [12]. The samples were withdrawn at 5, 10, 15, 20, 30, 45, and $60 \mathrm{~min}$ and replaced with an equal volume of same dissolution medium to maintain the sink conditions throughout the experiment. Samples withdrawn were suitably diluted with same dissolution medium, and the amount of the drug dissolved was estimated by Lab India Double Beam UV spectrophotometer (UV 3000+) at $258 \mathrm{~nm}$. The dissolution profiles were indicated in Table 5 and the parameters in Table 6.

\section{Preparation of dolutegravir sodium tablets}

Dolutegravir sodium tablets were prepared from the optimized solid dispersions using wet granulation technique. The drug concentration was maintained constant, while jackfruit seed starch and CCS concentrations were increased. The raw materials were individually weighed, passed through sieve 80 and blended for 15 min using double cone blender. The powder mixture of lactose, half amount of jackfruit starch was then converted into damp mass using sucrose solution. The damp mass was passed through sieve 20 to obtain granules and they were kept in tray dryer for drying at $60^{\circ} \mathrm{C}$ for $1 \mathrm{~h}$. The optimized solid dispersion was added to lactose granules and blended for $15 \mathrm{~min}$ using double cone blender. Flavoring agent was added to powdered mass and blended with $1 \%$ talc and magnesium stearate and compressed as

Table 4: Pre-formulation parameters of dolutegravir sodium solid dispersions

\begin{tabular}{llllll}
\hline Solid dispersion & Angle of repose $\left(^{\circ}\right)$ & Carr's index (\%) & Hausner's ratio & Average particle size $(\boldsymbol{\mu m})$ & Drug content $(\mathbf{m g})(\mathbf{M e a n} \pm \mathbf{S D})$ \\
\hline DP & 32 & 19 & 1.22 & 35 & - \\
DF1 & 14 & 1.19 & 174 & $46.22 \pm 0.54$ \\
DF2 & 25 & 13 & 1.20 & 168 & $44.85 \pm 0.41$ \\
DF3 & 23 & 12 & 1.16 & 175 & $49.62 \pm 0.77$ \\
DF4 & 21 & 13 & 1.18 & 176 \\
DF5 & 25 & 14 & 1.17 & 174 & $47.87 \pm 0.59$ \\
DF6 & 24 & 15 & 1.21 & $47.11 \pm 0.17$ \\
\hline
\end{tabular}

*DP indicates Dolutegravir sodium pure drug, $n=3$, SD: Standard deviation

Table 5: Drug release profiles of dolutegravir sodium solid dispersions prepared by fusion method

\begin{tabular}{|c|c|c|c|c|c|c|c|}
\hline \multirow[t]{2}{*}{ Time (in min) } & \multicolumn{7}{|c|}{ Cumulative $\%$ drug released (Mean \pm SEM) } \\
\hline & DP & DF1 & DF2 & DF3 & DF4 & DF5 & DF6 \\
\hline 5 & $5.35 \pm 1.17$ & $35.41 \pm 1.20$ & $39.95 \pm 0.14$ & $72.59 \pm 1.08$ & $71.87 \pm 1.88$ & $70.95 \pm 0.25$ & $67.38 \pm 1.08$ \\
\hline 10 & $7.08 \pm 1.78$ & $36.81 \pm 1.87$ & $45.27 \pm 2.01$ & $78.82 \pm 1.55$ & $80.71 \pm 1.40$ & $76.67 \pm 0.86$ & $76.00 \pm 1.69$ \\
\hline 15 & $9.67 \pm 0.15$ & $41.74 \pm 0.64$ & $56.71 \pm 1.28$ & $83.5 \pm 0.19$ & $82.28 \pm 2.11$ & $79.51 \pm 1.03$ & $79.03 \pm 2.04$ \\
\hline 20 & $10.9 \pm 2.07$ & $48.76 \pm 0.33$ & $61.35 \pm 0.61$ & $90.22 \pm 2.31$ & $90.33 \pm 0.65$ & $81.61 \pm 1.66$ & $80.33 \pm 0.48$ \\
\hline 30 & $11.64 \pm 1.07$ & $51.92 \pm 1.96$ & $70.40 \pm 1.81$ & $99.76 \pm 0.47$ & $94.53 \pm 0.31$ & $88.57 \pm 2.05$ & $86.53 \pm 0.23$ \\
\hline 45 & $12.22 \pm 1.88$ & $54.33 \pm 1.14$ & $84.23 \pm 0.34$ & $99.89 \pm 0.85$ & $98.57 \pm 1.22$ & $95.93 \pm 1.81$ & $91.10 \pm 1.26$ \\
\hline 60 & $13.34 \pm 1.64$ & $58.82 \pm 1.01$ & $88.31 \pm 2.14$ & $99.90 \pm 1.04$ & $98.87 \pm 1.77$ & $95.97 \pm 1.11$ & $91.43 \pm 1.09$ \\
\hline
\end{tabular}

$\mathrm{n}=3$, SEM: Standard error of mean

Table 6: In vitro dissolution parameters of dolutegravir sodium solid dispersions

\begin{tabular}{|c|c|c|c|c|c|c|c|c|}
\hline \multirow[t]{2}{*}{ Formulation } & \multirow[t]{2}{*}{$\begin{array}{l}\% \text { drug released } \\
\text { at } 60 \mathrm{~min}\end{array}$} & \multirow[t]{2}{*}{$\mathrm{T}_{50}(\mathrm{~min})$} & \multirow[t]{2}{*}{$T_{90}(\min )$} & \multirow[t]{2}{*}{$\mathrm{DE}_{20} \%$} & \multicolumn{2}{|c|}{$\begin{array}{l}\text { First order rate } \\
\text { constant }\end{array}$} & \multicolumn{2}{|c|}{$\begin{array}{l}\text { Hixson-Crowell cube } \\
\text { root plot }\end{array}$} \\
\hline & & & & & $K\left(\min ^{-1}\right)$ & $\mathbf{R}^{2}$ & $K\left(\min ^{-1 / 3}\right)$ & $\mathbf{R}^{2}$ \\
\hline DP & 26.86 & $>60$ & $>60$ & 12.5 & 0.007 & 0.448 & 0.004 & 0.732 \\
\hline DF1 & 58.82 & 28 & $>60$ & 35.0 & 0.024 & 0.906 & 0.008 & 0.895 \\
\hline DF2 & 88.31 & 13 & $>60$ & 42.5 & 0.033 & 0.912 & 0.020 & 0.906 \\
\hline DF3 & 99.90 & 3.0 & 20 & 72.5 & 0.078 & 0.938 & 0.039 & 0.960 \\
\hline DF4 & 98.87 & 2.5 & 20 & 67.5 & 0.068 & 0.922 & 0.029 & 0.940 \\
\hline DF5 & 95.97 & 2.5 & 35 & 65.0 & 0.048 & 0.901 & 0.022 & 0.950 \\
\hline DF6 & 91.43 & 3.0 & 40 & 62.5 & 0.053 & 0.912 & 0.015 & 0.927 \\
\hline
\end{tabular}


tablets using CLIT 10 station mini press. The compositions of various tablet formulations are given in Table 7.

\section{Evaluation of post-compression parameters}

The compressed tablets were further evaluated for post-compression parameters such as weight uniformity, hardness, friability, wetting time, dispersion test, and drug content [13]. The results are given in Table 8.

\section{Drug content uniformity}

Fast dissolving tablets of dolutegravir sodium from a batch were taken at random and were crushed to a fine powder. The powdered material was transferred into a $100 \mathrm{ml}$ volumetric flask and few $\mathrm{ml}$ of methanol was added to it. It was shaken occasionally for about $30 \mathrm{~min}$ and the volume was made up to $100 \mathrm{ml}$ by adding methanol. The resulting solution was set aside for few minutes and the supernatant solution was collected, filtered by Whatman filter paper. Then, the filtrate was subsequently diluted with phosphate buffer $\mathrm{pH} 6.8$ and the absorbance was measured at $258 \mathrm{~nm}$.

In vitro dissolution studies of dolutegravir sodium fast dissolving tablets

The dissolution test was carried out in United States Pharmacopoeia (USP) apparatus Type II (paddle) with $900 \mathrm{ml}$ of $6.8 \mathrm{pH}$ phosphate buffer as a dissolution medium. The samples were drawn at $5,10,15,20,30,45$, and $60 \mathrm{~min}$. The fresh volume of the medium was replaced with the withdrawn volume to maintain the sink conditions and constant volume throughout the experiment. Samples withdrawn were suitably diluted with same dissolution medium, and the amount of drug dissolved was estimated by ELICO SL UV - 210 at $258 \mathrm{~nm}$ and subsequently analyzed for the cumulative percentage of drug released. The dissolution studies on each formulation were conducted in triplicate. The drug release profiles for all the formulations are given in Tables 9-11.

Reverse-phase high-performance liquid chromatography (RP-HPLC) studies

The dissolution studies for the optimized formulations were further analyzed by RP-HPLC method to achieve the concurrency [14]. The dissolution test was carried out in USP Apparatus Type II (paddle) with $900 \mathrm{ml}$ of $6.8 \mathrm{pH}$ phosphate buffer as the dissolution medium. The samples were drawn at $5,10,15,20,30,45$, and $60 \mathrm{~min}$. The fresh volume of the medium was replaced with the withdrawn volume to maintain the sink conditions and constant volume throughout the experiment. Samples withdrawn were suitably diluted with the same dissolution medium, and the amount of drug dissolved was estimated by RP-HPLC. $40 \mu \mathrm{L}$ of the respective concentration solution is injected to HPLC using a syringe. The sample was run for $10 \mathrm{~min}$. The retention time and peak area were noted.

Table 7: Composition of dolutegravir sodium fast dissolving tablet formulations

\begin{tabular}{|c|c|c|c|c|c|c|c|c|c|c|}
\hline \multirow[t]{2}{*}{ Ingredient (mg/tablet) } & \multicolumn{10}{|c|}{ Formulations } \\
\hline & DFT1 & DFT2 & DFT3 & DFT4 & DFT5 & DFT6 & DFT7 & DFT8 & DFT9 & DFT10 \\
\hline DF3 solid dispersion & 125 & 125 & 125 & 125 & 125 & 125 & 125 & 125 & 125 & 125 \\
\hline Lactose & 157 & 149.5 & 142 & 134.5 & 127 & 119.5 & 112 & 127 & 119.5 & 112 \\
\hline JFS2 & - & 7.5 & 15 & 22.5 & 30 & 37.5 & 45 & - & - & - \\
\hline CCS & - & - & - & - & - & - & - & 30 & 37.5 & 45 \\
\hline Sucrose & 15 & 15 & 15 & 15 & 15 & 15 & 15 & 15 & 15 & 15 \\
\hline Pineapple flavor & Q.S & Q.S & Q.S & Q.S & Q.S & Q.S & Q.S & Q.S & Q.S & Q.S \\
\hline Talc & 1.5 & 1.5 & 1.5 & 1.5 & 1.5 & 1.5 & 1.5 & 1.5 & 1.5 & 1.5 \\
\hline Magnesium stearate & 1.5 & 1.5 & 1.5 & 1.5 & 1.5 & 1.5 & 1.5 & 1.5 & 1.5 & 1.5 \\
\hline Total weight & 300 & 300 & 300 & 300 & 300 & 300 & 300 & 300 & 300 & 300 \\
\hline
\end{tabular}

Q.S: Indicates quantity sufficient, CCS: Croscarmellose sodium, JFS2: jack fruit seed starch

Table 8: Post-compression parameters of various dolutegravir sodium fast dissolving tablet formulations

\begin{tabular}{|c|c|c|c|c|c|c|}
\hline Formulation & $\begin{array}{l}\text { Weight } \\
\text { uniformity (mg) }\end{array}$ & $\begin{array}{l}\text { Hardness }\left(\mathrm{kg} / \mathrm{cm}^{2}\right) \\
(\text { Mean } \pm S D)\end{array}$ & $\begin{array}{l}\text { Friability } \\
\text { (\% loss) }\end{array}$ & $\begin{array}{l}\text { Wetting } \\
\text { time (s) }\end{array}$ & $\begin{array}{l}\text { Dispersion } \\
\text { test }\end{array}$ & $\begin{array}{l}\text { Drug content } \\
\text { (mg/tablet) }(\text { Mean } \pm S D)\end{array}$ \\
\hline DFT1 & $298 \pm 2$ & $3.0 \pm 0.5$ & 0.3 & 180 & Passed & $45.64 \pm 0.5$ \\
\hline DFT 3 & $299 \pm 1$ & $3.0 \pm 0.5$ & 0.2 & 100 & Passed & $48.82 \pm 0.3$ \\
\hline DFT 4 & $300 \pm 3$ & $3.2 \pm 0.4$ & 0.2 & 75 & Passed & $47.79 \pm 0.6$ \\
\hline DFT 5 & $300 \pm 3$ & $3.5 \pm 0.2$ & 0.4 & 21 & Passed & $49.52 \pm 0.2$ \\
\hline DFT 6 & $299 \pm 2$ & $3.2 \pm 0.4$ & 0.1 & 20 & Passed & $49.76 \pm 0.6$ \\
\hline DFT 7 & $300 \pm 2$ & $3.0 \pm 0.5$ & 0.3 & 15 & Passed & $45.34 \pm 0.3$ \\
\hline DFT 8 & $300 \pm 1$ & $3.2 \pm 0.8$ & 0.4 & 36 & Passed & $47.74 \pm 0.4$ \\
\hline DFT 9 & $299 \pm 3$ & $3.2 \pm 0.4$ & 0.3 & 19 & Passed & $49.90 \pm 0.2$ \\
\hline DFT 10 & $300 \pm 2$ & $3.5 \pm 0.1$ & 0.2 & 50 & Passed & $48.10 \pm 0.2$ \\
\hline
\end{tabular}

$\mathrm{n}=3$, SD: standard deviation

Table 9: Dissolution profiles of dolutegravir sodium fast dissolving tablet formulations (DFT1-DFT6)

\begin{tabular}{|c|c|c|c|c|c|c|c|}
\hline \multirow[t]{2}{*}{ Time (min) } & \multicolumn{7}{|c|}{ Cumulative \% drug released (Mean \pm SEM) } \\
\hline & DP & DFT1 & DFT2 & DFT3 & DFT4 & DFT5 & DFT6 \\
\hline 5 & $10.73 \pm 0.28$ & $23.67 \pm 1.77$ & $27.83 \pm 2.04$ & $36.34 \pm 0.45$ & $39.31 \pm 0.58$ & $42.85 \pm 1.07$ & $48.72 \pm 1.22$ \\
\hline 15 & $19.35 \pm 0.97$ & $46.66 \pm 0.93$ & $56.45 \pm 0.09$ & $58.03 \pm 0.24$ & $62.18 \pm 0.17$ & $73.01 \pm 1.72$ & $77.60 \pm 0.47$ \\
\hline 20 & $21.81 \pm 1.02$ & $58.21 \pm 1.08$ & $67.20 \pm 0.35$ & $70.89 \pm 0.38$ & $75.19 \pm 1.45$ & $86.90 \pm 0.54$ & $91.84 \pm 0.83$ \\
\hline 30 & $23.28 \pm 0.55$ & $69.66 \pm 1.88$ & $74.54 \pm 1.66$ & $79.51 \pm 0.75$ & $80.36 \pm 1.68$ & $92.90 \pm 0.33$ & $99.00 \pm 0.97$ \\
\hline 45 & $24.44 \pm 0.26$ & $80.16 \pm 0.81$ & $93.90 \pm 1.87$ & $93.69 \pm 1.22$ & $96.03 \pm 1.99$ & $98.90 \pm 0.04$ & $99.69 \pm 1.11$ \\
\hline 60 & $26.86 \pm 1.26$ & $87.28 \pm 0.44$ & $97.21 \pm 2.01$ & $99.47 \pm 1.09$ & $97.47 \pm 0.43$ & $99.80 \pm 1.47$ & $99.77 \pm 1.05$ \\
\hline
\end{tabular}

$\mathrm{n}=3$, SEM: Standard error of mean, DP: Doultegravir sodium pure drug 
The runs were continued for all concentrations. The dissolution profiles were drawn using method as described earlier. Peak area versus time chromatogram and data are given in Table 12 and shown in Fig. 1. The comparative drug release profile of optimized formulation DFT6 using RP-HPLC and UV spectrophotometric analysis is given in Table 13.

Statistical analysis

The results obtained were statistically evaluated. As the procedures performed and the results obtained were in triplicates, the mean along with their standard deviations was calculated for drug content, and standard error of mean was calculated for drug dissolution profiles.

\section{Characterization studies}

Based on the dissolution studies, the optimized formulations were selected, and Fourier transfer infrared (FTIR), and differential scanning calorimetry (DSC) studies were performed to observe the drug-polymer interactions. X-Ray diffraction (XRD) studies were performed to detect the nature of formulations. Scanning electron microscopy (SEM) analysis was performed on JFS2, dolutegravir sodium, poloxamer-188, CCS, optimized solid dispersion, and fast dissolving tablet formulations to know surface characteristics. The results are shown in Figs. 2-5.

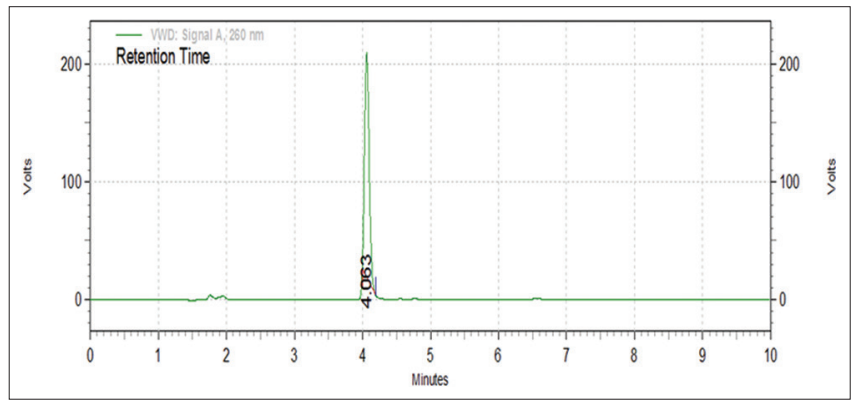

Fig. 1: Reverse-phase high-performance liquid chromatography chromatogram of dissolution sample (DFT6) at $20 \mathrm{~min}$ time interval
Accelerated stability studies

Accelerated stability studies were carried out on optimized formulations as per International Council for Harmonization of Technical Requirements for Registration of Pharmaceuticals for Human Use (ICH) guidelines. After the stability studies, the formulations were evaluated for physical parameters, drug content, and drug release studies. The results are indicated in Tables 14-16.

\section{RESULTS AND DISCUSSION}

Extraction of starch from jack fruit seeds

The starches extracted from jack fruit seeds were crisp, slightly granular, free-flowing and stable in nature.

Phytochemical screening of jack fruit seed flour and starch extracts The raw jack fruit seed powder and starches extracted were screened for the presence of various phytochemical constituents.

Evaluation of physicochemical properties of jack fruit seed powder and extracted starch

All the parameters evaluated for jack fruit seed powder and extracted starches were within specified Indian Pharmacopoeial limits. Of all the starches, JFS2 with high swelling and water absorption index was selected for preparation of fast dissolving tablets.

Preparation of dolutegravir sodium solid dispersions by fusion method

Solid dispersions of dolutegravir sodium were prepared using Poloxamer-188 in different ratios by fusion method. The composition of dolutegravir sodium solid dispersions prepared by the fusion method is given in Table 3.

\section{Evaluation of pre-formulation parameters}

Various pre-formulation parameters of dolutegravir sodium solid dispersions were evaluated. The obtained results are indicated in Table 4.

Table 10: Dissolution profiles of dolutegravir sodium fast dissolving tablet formulations (DFT7-DFT10)

\begin{tabular}{llllll}
\hline Time (min) & \multicolumn{2}{l}{ Cumulative \% drug released (Mean \pm SEM) } & & \\
\cline { 2 - 6 } & DP & DFT7 & DFT8 & DFT9 & DFT10 \\
\hline 5 & $10.73 \pm 0.47$ & $24.43 \pm 1.19$ & $41.51 \pm 0.57$ & $46.7 \pm 1.22$ & $65.96 \pm 0.44$ \\
10 & $14.16 \pm 0.81$ & $36.26 \pm 1.08$ & $55.75 \pm 1.44$ & $58.29 \pm 0.96$ & $67.27 \pm 0.72$ \\
15 & $19.35 \pm 1.16$ & $46.78 \pm 0.40$ & $71.94 \pm 1.65$ & $75.96 \pm 2.14$ & $76.98 \pm 1.70$ \\
20 & $21.81 \pm 1.78$ & $79.12 \pm 1.66$ & $87.91 \pm 2.11$ & $92.7 \pm 1.07$ & $91.41 \pm 1.93$ \\
30 & $23.28 \pm 1.94$ & $91.62 \pm 1.54$ & $91.64 \pm 1.08$ & $98.2 \pm 1.42$ & $93.73 \pm 2.04$ \\
45 & $24.44 \pm 0.65$ & $94.55 \pm 0.70$ & $97.36 \pm 0.37$ & $98.79 \pm 0.90$ & $95.23 \pm 1.62$ \\
60 & $26.86 \pm 0.83$ & $95.80 \pm 0.21$ & $97.66 \pm 0.82$ & $99.69 \pm 0.14$ & 98.78 \\
\hline
\end{tabular}

$\mathrm{n}=3$, SEM: Standard error of mean, DP: Dolutegravir sodium pure drug, DMT: Dolutegravir marketed tablet

Table 11: Dissolution parameters of dolutegravir sodium fast dissolving tablets

\begin{tabular}{|c|c|c|c|c|c|c|c|c|}
\hline \multirow[t]{2}{*}{ Formulation } & \multirow{2}{*}{$\begin{array}{l}\% \text { drug released } \\
\text { at } 60 \mathrm{~min}\end{array}$} & \multirow[t]{2}{*}{$T_{50}(\min )$} & \multirow[t]{2}{*}{$T_{90}(\min )$} & \multirow[t]{2}{*}{$\mathrm{DE}_{20} \%$} & \multicolumn{2}{|c|}{ First order } & \multicolumn{2}{|c|}{ Hixson crowell } \\
\hline & & & & & $\mathrm{K}\left(\mathrm{min}^{-1}\right)$ & $\mathbf{R}^{2}$ & $\mathrm{~K}\left(\mathrm{~min}^{-1 / 2}\right)$ & $\mathbf{R}^{2}$ \\
\hline DP & 26.86 & $>60$ & $>60$ & 12.5 & 0.007 & 0.448 & 0.004 & 0.732 \\
\hline DFT2 & 97.21 & 12.5 & 44 & 42.5 & 0.059 & 0.929 & 0.041 & 0.860 \\
\hline DFT3 & 99.47 & 11 & 43 & 45 & 0.071 & 0.960 & 0.045 & 0.860 \\
\hline DFT4 & 97.47 & 10 & 40 & 50 & 0.062 & 0.976 & 0.041 & 0.955 \\
\hline DFT5 & 99.80 & 7 & 40 & 50 & 0.082 & 0.960 & 0.051 & 0.947 \\
\hline DFT6 & 99.77 & 6 & 20 & 57.5 & 0.082 & 0.982 & 0.053 & 0.980 \\
\hline DFT7 & 95.80 & 16 & 30 & 35 & 0.058 & 0.918 & 0.042 & 0.880 \\
\hline DFT8 & 97.66 & 8 & 27 & 55 & 0.004 & 0.822 & 0.042 & 0.869 \\
\hline DFT9 & 99.69 & 7 & 20 & 47.5 & 0.111 & 0.990 & 0.050 & 0.985 \\
\hline DFT10 & 98.09 & 45 & 20 & 60 & 0.059 & 0.898 & 0.036 & 0.891 \\
\hline DMT & 89.72 & 17 & $>60$ & 15 & 0.055 & 0.943 & 0.033 & 0.970 \\
\hline
\end{tabular}

DP: Dolutegravir sodium pure drug, DMT: Dolutegravir marketed tablet 
Table 12: Drug release profiles of optimized formulation (DFT6) by RP-HPLC analysis

\begin{tabular}{ll}
\hline Time (min) & Cumulative \% drug released (Mean \pm SEM) \\
\hline 5 & $40.56 \pm 1.08$ \\
10 & $50.86 \pm 1.64$ \\
15 & $73.25 \pm 0.87$ \\
20 & $89.36 \pm 1.17$ \\
30 & $96.32 \pm 2.13$ \\
45 & $98.10 \pm 1.77$ \\
\hline$n=3$ SEM: Standard
\end{tabular}

Table 13: Comparative drug release profiles of optimized formulation (DFT6) by RP-HPLC and UV spectrophotometry analysis

\begin{tabular}{llc}
\hline Time (min) & \multicolumn{2}{c}{ Cumulative \% drug released (Mean \pm SEM) } \\
\cline { 2 - 3 } & DFT6 (UV) & DFT6 (HPLC) \\
\hline 5 & $48.72 \pm 1.22$ & $40.56 \pm 1.08$ \\
10 & $58.42 \pm 1.54$ & $50.86 \pm 1.64$ \\
15 & $77.60 \pm 0.47$ & $73.25 \pm 0.87$ \\
20 & $91.84 \pm 0.83$ & $89.36 \pm 1.17$ \\
30 & $99.00 \pm 0.97$ & $96.32 \pm 2.13$ \\
45 & $99.69 \pm 1.11$ & $98.10 \pm 1.77$ \\
60 & $99.77 \pm 1.05$ & $98.45 \pm 1.24$ \\
\hline
\end{tabular}

$\mathrm{n}=3$, SEM: Standard error of mean, RP-HPLC: Reverse-phase high-performance liquid chromatography chromatogram, UV: Ultraviolet
In vitro dissolution studies of dolutegravir sodium solid dispersions

Formulation DF3, prepared in 1:3 ratios of dolutegravir sodium and Poloxamer-188 showed maximum drug release proving that solid dispersion technique enhances drug release as suggested by earlier studies [15]. The fusion technique used for the formulation of solid dispersions was also proved to be most advantageous as suggested earlier [16]. Employment of hydrophilic polymer was proved to be effective in dissolution enhancement [17]. The dissolution profiles of dolutegravir sodium solid dispersions are given in Table 5.

\section{Formulation of dolutegravir sodium fast dissolving tablets}

Dolutegravir sodium fast dissolving tablets with various concentrations of JFS2 and CCS were prepared by wet granulation technique. Formulations DFT2 to DFT7 were prepared using $2.5-15 \%$ of JFS2. Formulations DFT8 to DFT10 were prepared using $10-15 \%$ of CCS. Formulation DFT1 does not contain any superdisintegrant. The compositions are given in Table 7.

\section{Evaluation of post-compression parameters}

The wet granulation process was found to be suitable for compressing prepared granules as fast dissolving tablets [18,19]. All the batches of tablets were compressed under identical conditions to minimize processing variables. Then, the compressed tablets were further evaluated for post-compression parameters. The results are given in Table 8. Weight uniformity, hardness, and friability loss of all tablet formulations were within the specified limits. Thus, all the batches of tablet formulations were found to be stable and suitable for further studies.
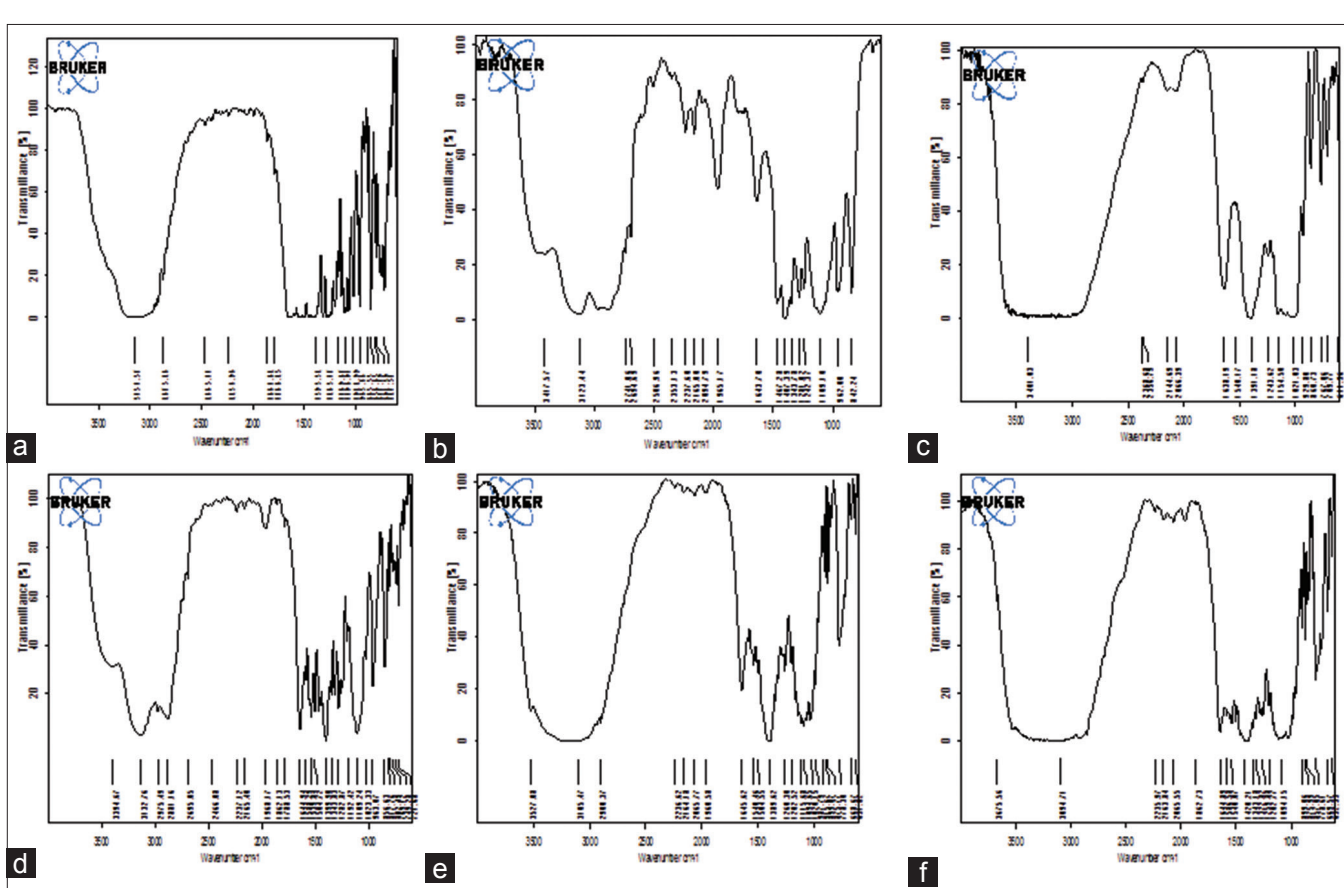

d

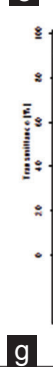

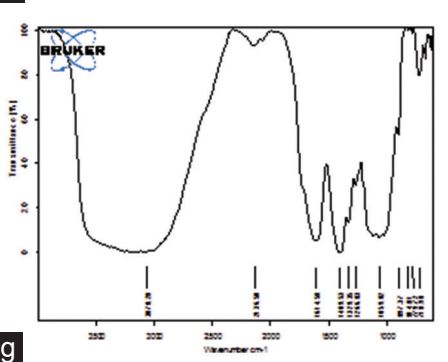

(1)

Fig. 2: Fourier transfer infrared spectra: (a) Dolutegravir sodium pure drug (b) Poloxamer-188 (c) DF3 solid dispersion (d) JFS2 (e) DFT6 Formulation (f) CCS (g) DFT9 formulation. JFS2: Jack fruit seed starch extracted with $0.1 \%$ sodium hydroxide, CCS: Croscarmellose sodium, DF3: Solid dispersion of dolutegravir \pm Poloxamer-188 in 1:3 ratio, DFT6: Solid dispersion of DF3 with 12.5\% JFS2, DFT9: Solid dispersion of DF3 with $12.5 \%$ CCS 

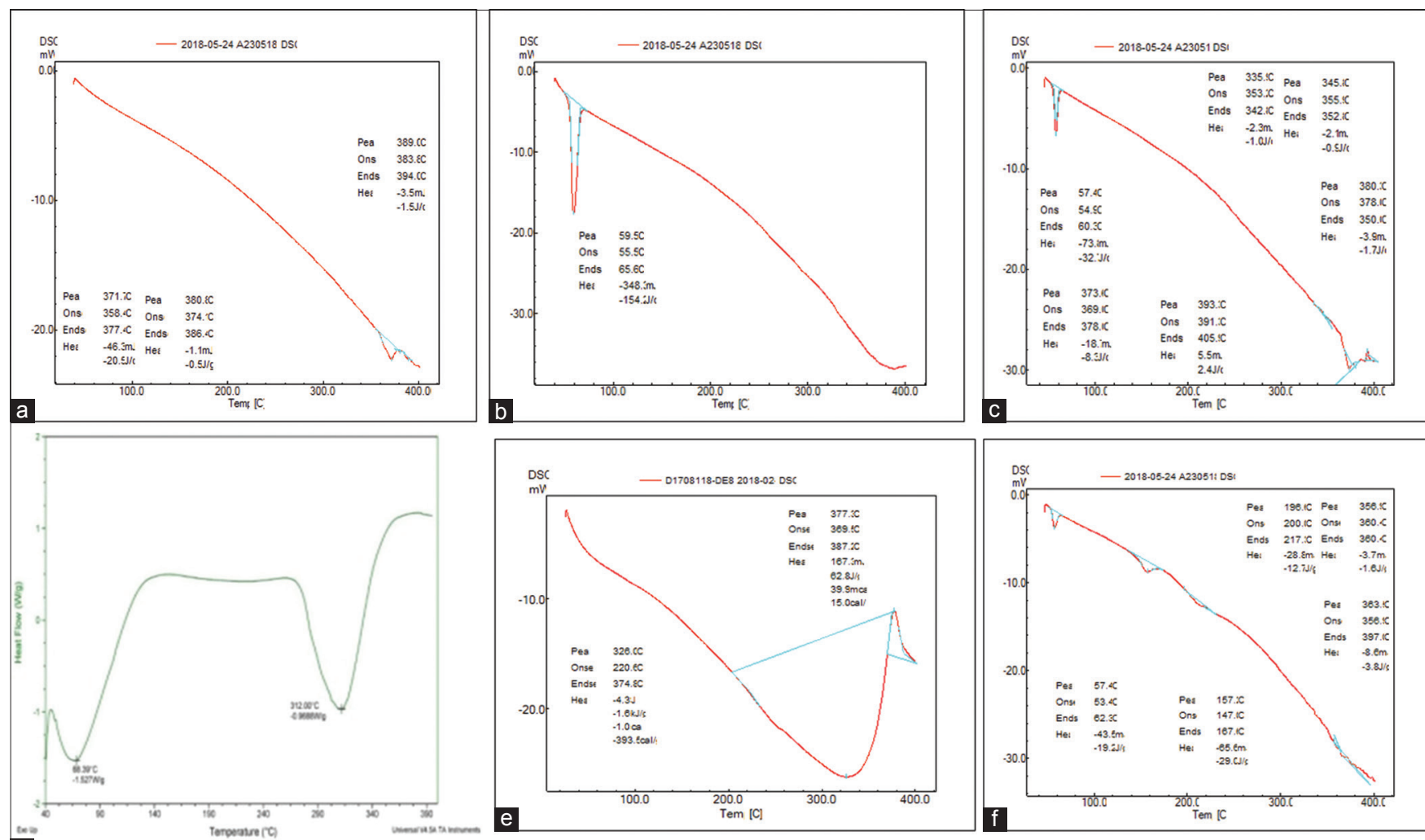

d

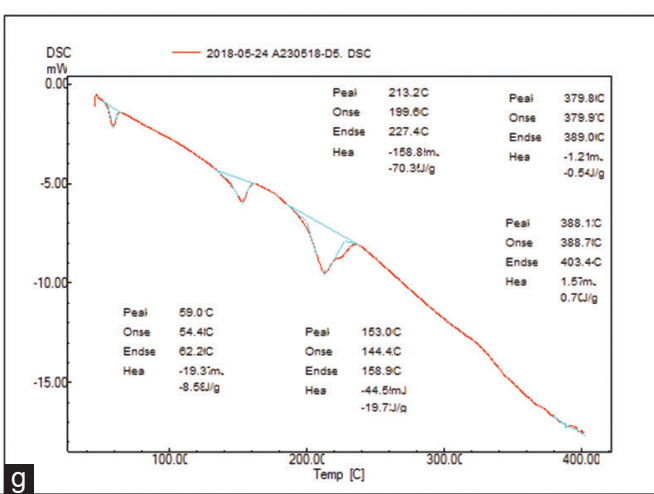

Fig. 3: Differential scanning calorimetry thermograms: (a) Dolutegravir sodium pure drug (b) Poloxamer-188 (c) DF3 Solid Dispersion (d) JFS2 (e) DFT6 formulation (f) CCS (g) DFT9 formulation. JFS2: Jack fruit seed starch extracted with 0.1\% sodium hydroxide, CCS: Croscarmellose sodium, DF3: Solid dispersion of dolutegravir \pm Poloxamer-188 in 1:3 ratio, DFT6: Solid dispersion of DF3 with 12.5\% JFS2, DFT9: Solid dispersion of DF3 with $12.5 \%$ CCS

In vitro dissolution studies of dolutegravir sodium fast dissolving tablets

Dissolution studies were carried on all fast dissolving tablet formulations using USP paddle method (Apparatus II) with phosphate buffer $\mathrm{pH} 6.8$ as dissolution medium by maintaining the bath temperature at $37 \pm 1^{\circ} \mathrm{C}$ and the paddles were operated at $50 \mathrm{rpm}$. The dissolution profiles of all the fast dissolving tablets are given in Tables 9 and 10.

It was observed that the type of starch as superdisintegrant and its proportion in the formulation have greatly influenced the dissolution parameters of various formulations. Formulation DFT6 containing $12.5 \% \mathrm{w} / \mathrm{w}$ of JFS2 as superdisintegrant exhibited similar dissolution profile with that of the formulation DFT9 prepared by $12.5 \% \mathrm{w} / \mathrm{w}$ CCS. Several studies have been conducted earlier indicating the effect of superdisintegrants over solubility enhancement [20]. They suggest the usage of a mixture of superdisintegrants rather than single. Solid dispersions were already proved to be effective in dissolution rate enhancement [21]. Along with this, if starch was also incorporated, it could increase the dissolution rate more. Natural derivatives are nowadays playing an important role in solubility enhancement [22]. Recent studies suggest the application of natural starches as superdisintegrants. They also prove the equal efficacy of natural starches and already established superdisintegrants.

\section{RP-HPLC studies}

The dissolution studies for the optimized formulations were further analyzed by RP-HPLC method. The dissolution profiles obtained from RP-HPLC technique showed almost similar dissolution profile as that of UV spectrophotometric analysis which indicated the accuracy of data.

\section{Characterization studies}

Based on the dissolution studies performed on all the formulations, the optimized formulations were selected, and the following studies were done.

\section{FTIR spectroscopic analysis}

The FTIR spectral investigations were conducted on dolutegravir pure drug, poloxamer-188, solid dispersion DF3, JFS2, CCS, DFT6, and DFT9 


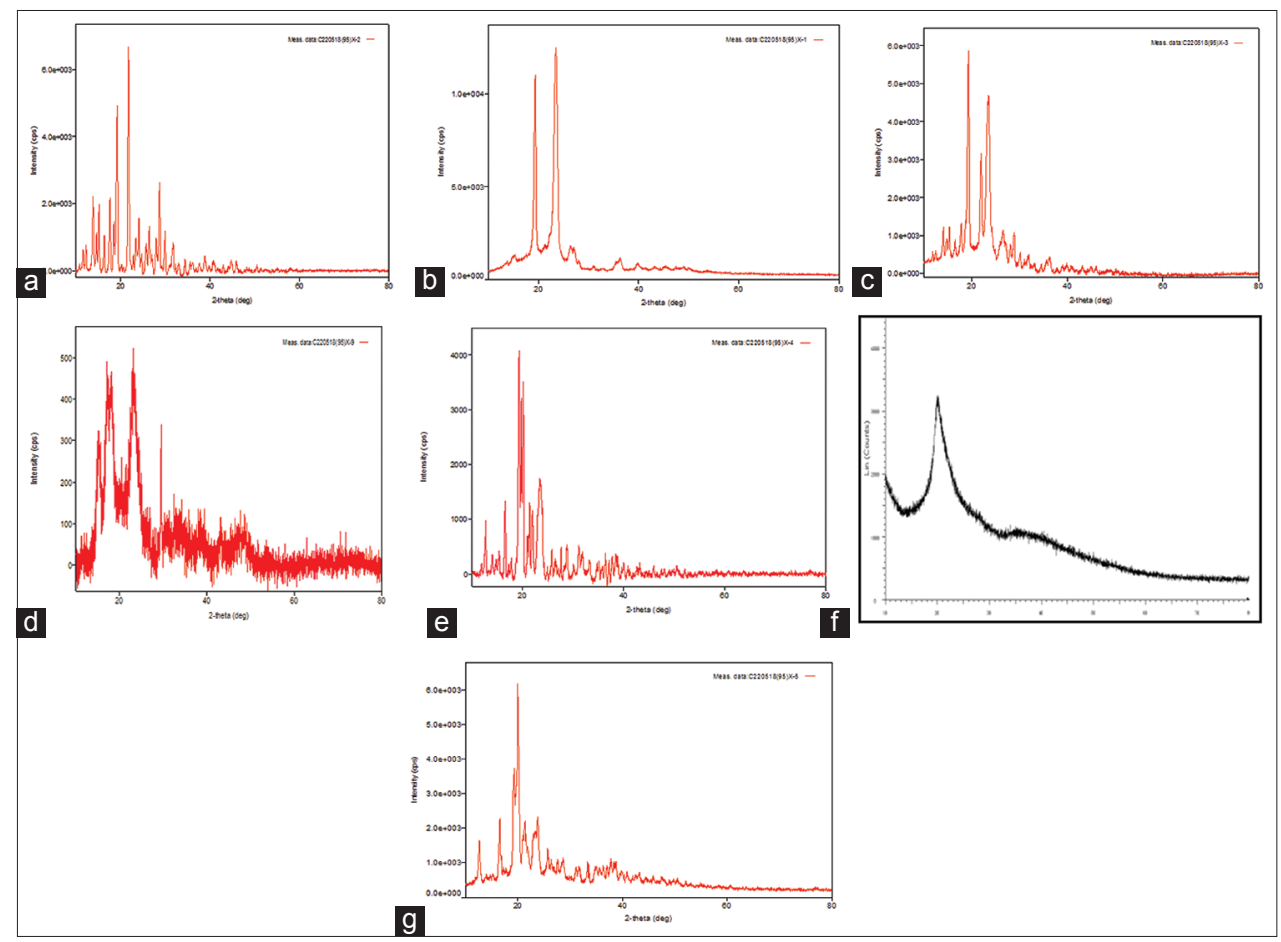

Fig. 4: X-ray diffraction diffractograms: (a) Dolutegravir sodium pure drug (b) Poloxamer-188 (c) DF3 solid dispersion (d) JFS2 (E) DFT6 formulation (f) CCS (g) DFT9 formulation. JFS2: Jack fruit seed starch extracted with $0.1 \%$ sodium hydroxide, CCS: Croscarmellose sodium, DF3: Solid dispersion of dolutegravir \pm Poloxamer-188 in 1:3 ratio, DFT6: Solid dispersion of DF3 with 12.5\% JFS2, DFT9: Solid dispersion of DF3 with $12.5 \%$ CCS
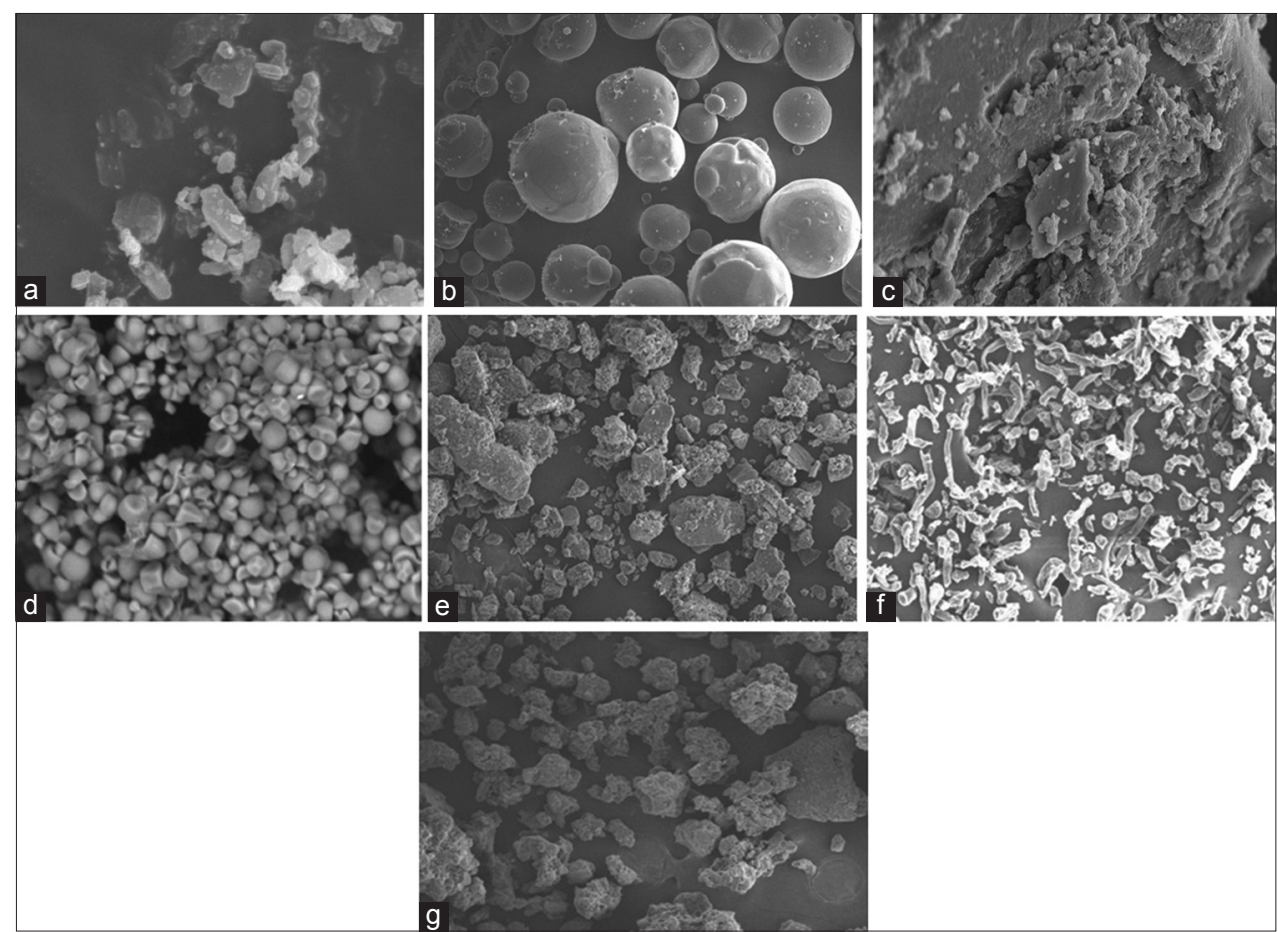

Fig. 5: Scanning electron microscopy images: (a) Dolutegravir sodium pure drug (b) Poloxamer-188 (c) DF3 solid dispersion (d) JFS2 (e) DFT6 Formulation (f) CCS (g) DFT9 formulation. JFS2: Jack fruit seed starch extracted with 0.1\% sodium hydroxide, CCS: Croscarmellose sodium, DF3: Solid dispersion of dolutegravir \pm poloxamer-188 in 1:3 ratio, DFT6: Solid dispersion of DF3 with 12.5\% JFS2, DFT9: Solid dispersion of DF3 with $12.5 \%$ CCS

formulations. The pure drug dolutegravir sodium exhibited sharp peak at $2234.96 \mathrm{~cm}^{-1}, 1393.32 \mathrm{~cm}^{-1}, 856.65 \mathrm{~cm}^{-1}$, and $885.53 \mathrm{~cm}^{-1}$ indicating the presence of $\mathrm{C}-\mathrm{N}$ stretching, $\mathrm{C} \equiv \mathrm{C}$ stretching, $\mathrm{C}-\mathrm{O}-\mathrm{C}$ stretching, $\mathrm{C}-\mathrm{H}$ bending, and Ar-H bending. For Poloxamer sharp peaks at $2237.60 \mathrm{~cm}^{-1}$,
$2165.00 \mathrm{~cm}^{-1}$, and $842.24 \mathrm{~cm}^{-1}$ indicated $\mathrm{C}-\mathrm{N}$ stretching, $\mathrm{C} \equiv \mathrm{C}$ stretching, and C-H bending. For DF3 solid dispersion, sharp peaks at $2237.12 \mathrm{~cm}^{-1}$, $2165.40 \mathrm{~cm}^{-1}, 1391.18 \mathrm{~cm}^{-1}$, and $842.24 \mathrm{~cm}^{-1}$ indicated C-N stretching, $\mathrm{C} \equiv \mathrm{C}$ stretching, C-O-C stretching, and Ar-H bending. For JFS2 sharp 
Table 14: Post-compression parameters of formulations DFT6 and DFT9 under accelerated stability conditions

\begin{tabular}{lllllll}
\hline Formulation & Storage condition & Hardness $\left.\mathbf{( k g} / \mathbf{c m}^{2}\right)$ & Friability $(\%$ loss) & Dispersion test & Wetting time (s) & Drug content (mg/tablet) \\
\hline DFT6 & Before Storage & $3.2 \pm 0.4$ & 0.2 & Passed & 20 & $49.76 \pm 0.6$ \\
& $25 \pm 2^{\circ} \mathrm{C}, 60 \pm 5 \%$ RH & $3.1 \pm 0.2$ & 0.3 & Passed & 21 & $49.00 \pm 0.2$ \\
& $40 \pm 2^{\circ} \mathrm{C}, 75 \pm 5 \%$ RH & $3.2 \pm 0.4$ & 0.2 & Passed & 19 & $48.86 \pm 0.2$ \\
DFT9 & Before Storage & $3.2 \pm 0.1$ & 0.2 & Passed & 20 & $49.90 \pm 0.6$ \\
& $25 \pm 2^{\circ} \mathrm{C}, 60 \pm 5 \%$ RH & $3.2 \pm 0.4$ & 0.3 & Passed & 19 & $49.50 \pm 0.6$ \\
& $40 \pm 2^{\circ} \mathrm{C}, 75 \pm 5 \%$ RH & $3.1 \pm 0.2$ & 0.3 & Passed & 20.6 \\
\hline
\end{tabular}

Table 15: Accelerated stability studies dissolution profiles of formulation (DFT6)

\begin{tabular}{llll}
\hline $\begin{array}{l}\text { Time } \\
\text { (min) }\end{array}$ & $\begin{array}{l}\text { Before } \\
\text { storage }\end{array}$ & $\begin{array}{l}\mathbf{2 5} \pm \mathbf{2}^{\circ} \mathbf{C}, \\
\mathbf{6 0 \pm 5 \%} \mathbf{R H}\end{array}$ & $\begin{array}{l}\mathbf{4 0 \pm 2} \mathbf{}^{\circ} \mathbf{C}, \\
\mathbf{7 5} \mathbf{5 \%} \mathbf{R H}\end{array}$ \\
\hline 5 & $48.72 \pm 1.22$ & $48.69 \pm 1.20$ & $45.90 \pm 0.74$ \\
10 & $58.42 \pm 1.54$ & $58.40 \pm 1.48$ & $55.58 \pm 1.11$ \\
15 & $77.60 \pm 0.47$ & $77.58 \pm 1.52$ & $74.23 \pm 2.04$ \\
20 & $91.84 \pm 0.83$ & $91.82 \pm 1.71$ & $87.65 \pm 1.99$ \\
30 & $99.00 \pm 0.97$ & $99.00 \pm 0.54$ & $95.09 \pm 1.73$ \\
45 & $99.69 \pm 1.11$ & $99.65 \pm 0.87$ & $95.41 \pm 1.25$ \\
60 & $99.77 \pm 1.05$ & $99.74 \pm 0.33$ & $96.22 \pm 1.81$ \\
\hline
\end{tabular}

$\mathrm{n}=3, \mathrm{RH}$ : Relative humidity

Table 16: Accelerated stability studies dissolution profiles of formulation (DFT9)

\begin{tabular}{llll}
\hline $\begin{array}{l}\text { Time } \\
\text { (min) }\end{array}$ & $\begin{array}{l}\text { Before } \\
\text { storage }\end{array}$ & $\begin{array}{l}\mathbf{2 5} \pm \mathbf{2}^{\circ} \mathbf{C}, \\
\mathbf{6 0} \pm \mathbf{5 \%} \mathbf{R H}\end{array}$ & $\begin{array}{l}\mathbf{4 0} \pm \mathbf{2}^{\circ} \mathbf{C}, \\
\mathbf{7 5} \pm \mathbf{5 \%} \mathbf{R H}\end{array}$ \\
\hline 5 & $46.7 \pm 1.22$ & $46.69 \pm 1.19$ & $46.65 \pm 1.07$ \\
10 & $58.29 \pm 0.96$ & $58.26 \pm 1.78$ & $58.23 \pm 2.88$ \\
15 & $75.96 \pm 2.14$ & $75.93 \pm 1.44$ & $75.30 \pm 1.44$ \\
20 & $92.7 \pm 1.07$ & $92.68 \pm 1.05$ & $92.63 \pm 0.79$ \\
30 & $98.2 \pm 1.42$ & $98.18 \pm 2.11$ & $98.14 \pm 0.23$ \\
45 & $98.79 \pm 0.90$ & $98.75 \pm 0.53$ & $98.70 \pm 0.15$ \\
60 & $99.69 \pm 0.14$ & $99.65 \pm 1.73$ & $99.61 \pm 0.09$ \\
\hline
\end{tabular}

$\mathrm{n}=3$, RH: Relative humidity

peaks at $1391.18 \mathrm{~cm}^{-1}$ and $860.73 \mathrm{~cm}^{-1}$ were observed indicating the presence of C-O-C stretching and Ar-H bending. For DFT6 tablet formulation, sharp peaks at $2236.62 \mathrm{~cm}^{-1}, 2164.18 \mathrm{~cm}^{-1}, 1389.62 \mathrm{~cm}^{-1}$, and $875.77 \mathrm{~cm}^{-1}$ indicated the presence of $\mathrm{C}-\mathrm{N}$ stretching, $\mathrm{C} \equiv \mathrm{C}$ stretching, C-O-C stretching, C-H bending, and Ar-H bending. For CCS, a sharp peak at $2136.50 \mathrm{~cm}^{-1}$ and $897.37 \mathrm{~cm}^{-1}$ indicated the presence of $\mathrm{C} \equiv \mathrm{C}$ stretching and Ar-H bending. For DFT9 formulation, a sharp peak at $2163.84 \mathrm{~cm}^{-1}, 857.05 \mathrm{~cm}^{-1}$, and $899.06 \mathrm{~cm}^{-1}$ indicated the presence of $\mathrm{C} \equiv \mathrm{C}$ stretching, $\mathrm{C}-\mathrm{H}$ bending, and $\mathrm{Ar}-\mathrm{H}$ bending. The remaining peaks were unaltered indicating that there was no drug and excipients interaction. The detailed spectral elucidations are shown in Fig. 2.

DSC

A differential scanning calorimeter (DSC 200F3, Shimadzu) was used to obtain the DSC curves of dolutegravir sodium pure drug, poloxamer-188, solid dispersion DF3, CCS, DFT6, and DFT9 formulations representing the rates of heat uptake. The DSC results revealed that a sharp peak for dolutegravir sodium was observed at $371.78^{\circ} \mathrm{C}, 380^{\circ} \mathrm{C}$, and $389^{\circ} \mathrm{C}$. A sharp endothermic peak for poloxamer- 188 was observed at $59.5^{\circ} \mathrm{C}$. Sharp and broad peaks for DF3 were observed at $57.47^{\circ} \mathrm{C}, 345.80^{\circ} \mathrm{C}$, and $373.68^{\circ} \mathrm{C}$. Broad endothermic peaks for jack fruit seed starch were observed at $68.39^{\circ} \mathrm{C}$ and $312.00^{\circ} \mathrm{C}$. For DFT6, a broad peak and sharp peak were observed at $57.47^{\circ} \mathrm{C}, 356.96^{\circ} \mathrm{C}$, and $363.59^{\circ} \mathrm{C}$. Sharp endothermic peaks for CCS were observed at $326.00^{\circ} \mathrm{C}$ and $377.3^{\circ} \mathrm{C}$. A broad and sharp peak for DFT9 was observed at $59.01^{\circ} \mathrm{C}$, $153.00^{\circ} \mathrm{C}$, and $379.86^{\circ} \mathrm{C}$. These studies revealed that there were no drug and excipient interactions which were confirmed by obtaining similar thermographic peaks at respective temperatures. The detailed thermographs are shown in Fig. 3.

\section{Powder XRD (PXRD)}

PXRD patterns were traced employing X-ray diffractometer Shimadzu and DSC-60, Germany for all the samples using Nickel filter, CuK $(\alpha)$ radiation, a current of $20 \mathrm{~mA}$ and receiving slit of 0.2 inches. PXRD studies of dolutegravir sodium showed several sharp peaks from 10 to $40 \theta^{\circ}$. The PXRD studies for poloxamer 188 showed only two sharp peaks at $20-30 \theta^{\circ}$. The solid dispersion prepared by dolutegravir sodium and polaxmer-188 revealed that sharp peaks corresponding to the polymer were observed at $20-30 \theta^{\circ}$. This indicated that the crystallinity of the pure drug was greatly reduced by solid dispersion formulation having poloxamer 188. PXRD studies of JFS2 showed sharp peaks at 17-33 and CCS at $20.3 \theta^{\circ}$. DFT6 and DFT9 formulations exhibited peaks at 3-30 $\theta^{\circ}$. The PXRD patterns are shown in Fig. 4.

\section{SEM}

SEM images were taken for Dolutegravir sodium pure drug, poloxamer-188, solid dispersion DF3, JFS2, CCS and a blend of DF3 and jack fruit starch. SEM photographs of dolutegravir sodium exhibited high crystallinity of drug with several planes of the surface. Poloxamer-188 exhibited a spherical shaped granular form of beads. Solid dispersion DF3 showed that the drug was absorbed on to the spherical beads and thereby the crystallinity of the drug is greatly reduced. The Jack fruit starch, JFS2 exhibited spherical free flowing with a low dense form of starch grains without having any intact resinous or mucilaginous mass and CCS exhibited crystallinity. The SEM image of a blend of Dolutegravir DF3 and Jack fruit starch (DFT6 formulation) exhibited the well-distributed spherical shaped intragranular spaces and bead-like crystals were clearly observed. The SEM image of a blend of DF3 and CCS (DFT9 tablet formulation) exhibited the well distributed sphericalshaped bead-like crystals. The SEM images were clearly shown in Fig. 5 .

Accelerated stability studies of dolutegravir sodium fast dissolving tablets

The fast dissolving tablets DFT6 and DFT9 containing dolutegravir sodium which showed good in vitro performance were subjected to accelerated stability studies. These studies were carried out by investigating the effect of temperature on the physical properties and drug release from fast dissolving tablets. The results of these studies are given in Tables 14-16. The results thus indicated that there were no visible and physical changes observed in the frequency-discrimination thresholds (FDTs) even after storage. Weight uniformity, hardness, friability, wetting time, dispersion test, and drug content were found to be uniform before and after storage at different conditions. It was also observed that there was no significant change in drug release from the FDTs. Thus, the drug release characteristics of FDTs designed were found to be quite stable.

\section{CONCLUSION}

The starch JFS2 extracted from jack fruit seeds with $0.1 \%$ sodium hydroxide is found to be the best and is used as superdisintegrant for preparation of fast dissolving tablets. Dolutegravir sodium solid dispersions were prepared using various concentrations of JFS2 and poloxamer-188 and were subjected to in vitro dissolution studies. From these studies, it was observed that the proportion of starch as superdisintegrant has influenced the dissolution parameters of various formulations. Dolutegravir sodium fast dissolving tablets were prepared using various concentrations of JFS2 and CCS and were subjected to in vitro dissolution studies. From these studies, it was observed that the 
proportion of starch as superdisintegrant has influenced the dissolution parameters of various formulations. Similar dissolution profiles were observed for formulations, DFT6 containing $12.5 \% \mathrm{w} / \mathrm{w}$ of JFS2 and DFT 9 containing $12.5 \% \mathrm{w} / \mathrm{w}$ of CCS as superdisintegrants. The possible mechanism of superdisintegrant effect of these starches might be the rapid uptake of water, followed by swelling which causes the elevation of hydrostatic pressure in a tablet that leads to faster disintegration of tablets. The optimized formulations when subjected to FTIR and DSC analysis showed no drug-excipient interactions. Similarly, XRD studies were conducted to know the crystalline and amorphous nature of the samples. The optimized formulations DFT6 and DFT9 were also subjected to accelerated stability studies, which revealed that there were no significant changes in physical parameters and drug content even after the stability studies at various storage conditions which indicated that these formulations were stable.

\section{ACKNOWLEDGMENTS}

The authors are thankful to the management of Chebrolu Hanumaiah Institute of Pharmaceutical Sciences for their sheer support throughout the work. The authors also express their thanks to M/s. Dr. Reddy's Laboratories, Hyderabad, India, for their generous gift sample of Dolutegravir sodium and Dr. D. Hari Narayana, Nishka Labs, Hyderabad, and his team for their extensive support in conducting DSC, SEM, and XRD studies.

\section{AUTHOR'S CONTRIBUTIONS}

Dr. Vidyadhara Suryadevara the guarantor of this study has designed and supervised the experimental process. Mr. Sundeep Mupparaju and Ms. Sailaja Yallam have carried out the experiments and analyzed the results. Mr. Sandeep Doppalapudi has contributed in preparation and revision of the manuscript. Dr. Sasidhar Reddyvallam L C and Dr. Ramu Anne have reviewed the manuscript.

\section{CONFLICTS OF INTEREST}

The authors declare that they have no conflicts of interest.

\section{REFERENCES}

1. Saharan VA, Kukkar V, Kataria M, Gera M, Chowdhury PK. Dissolution enhancement of drugs, Part I: Technologies and effect of carriers. Int J Health Res 2009;2:107-24.

2. Dhirendra K, Lewis S, Udupa N, Atin K. Solid dispersions: A review. Pak J Pharm Sci 2009;22:234-46.

3. Clotet B, Feinberg J, van Lunzen J, Khuong-Josses MA, Antinori A, Dumitru I, et al. Once-daily dolutegravir versus darunavir plus ritonavir in antiretroviral-naive adults with HIV-1 infection (FLAMINGO): 48 week results from the randomised open-label phase $3 \mathrm{~b}$ study. Lancet 2014;383:2222-31

4. Elzi L, Erb S, Furrer H, Cavassini M, Calmy A, Vernazza P, et al. Adverse events of raltegravir and dolutegravir. AIDS 2017;31:1853-8.
5. Raffi F, Rachlis A, Stellbrink HJ, Hardy WD, Torti C, Orkin C, et al. Once-daily dolutegravir versus raltegravir in antiretroviral-naive adults with HIV-1 infection: 48 week results from the randomised, doubleblind, non-inferiority SPRING-2 study. Lancet 2013;381:735-43.

6. Chauhan V, Kumar K, Teotia D. Fast dissolving tablets: A promising approach for drug delivery. Univ J Pharm Res 2017;2:58-4

7. Fateatun N, Jiaur RM, Sultan MM, Sorifa A, Aminul IT, Ahmed M. Physicochemical properties of flour and extraction of starch from Jack Fruit seed. Int J Nut Food Sci 2014:3:347-54

8. Menaka T, Nagaraja G, Yogesh DB, Sunil Kumar US, Prakash L. Physicochemical properties of flour and isolated starch from Jackfruit seeds (Artocarpus Heterophyllus). Res J Pharm Sci 2011;1:14-8.

9. Vidyadhara S, Sasidhar RL, Lakshmi HD, Vijetha P, Vijetha K. Studies on jack fruit seed starch as a novel natural superdisintegrant for the design and evaluation of Irbesartan fast dissolving tablets. Int Med Res 2017;6:280-91

10. Okunlola A, Odeku OA. Comparative evaluation of starches obtained from Dioscorea species as intragranular tablet disintegrants. J Drug Del Sci Technol 2008;18:445-7.

11. Sharda S, Bishambar S, Kirtika M, Monalisha N, Neha K, Shalini M. Solid dispersions: A tool for improving the solubility and dissolution of metronidazole. Int J Drug Del 2013;5:94-8.

12. Appa RB, Shivalingam M, Kishore RY, Somesekhara R, Rajesh K, Sunitha N. Formulation and evaluation of aceclofenac solid dispersions for dissolution rate enhancement. Int J Pharm Sci Drug Res 2010;2:146-50.

13. Sreenivas SA, Gadad A, Patil M. Formulation and evaluation of Ondansetron hydrochloride directly compressed mouth dissolving tablets. Indian Drugs 2006;4:35-7.

14. Bhavar GB, Pekamwar SS, Aher KB, Thorat RS, Chaudhari SR. Highperformance liquid chromatographic and high-performance thin-layer chromatographic method for the quantitative estimation of dolutegravir sodium in bulk drug and pharmaceutical dosage form. Sci Pharm 2016;84:305-20.

15. Dharna A, Neelam S, Sukhbir S, Sandeep A. Solid dispersions: A review on drug delivery system and solubility enhancement. Int J Pharm Sci Res 2013;4:2094-105.

16. Shashikumar Y, Veena M, Srinivas M. Solid dispersion technique to enhance the solubility and dissolution rate of Aripiprazole by fusion method. Int J Pharm Pharm Sci 2016;8:187-92.

17. Pratik SD, Sushma V, Puja S. Fast dissolving tablet using solid dispersion technique: A review. Int J Curr Pharm Res 2017;9:1-4

18. Sharma A, Jain CP. Preparation and characterization of solid dispersions of carvedilol with PVP K30. Res Pharm Sci 2010;5:49-56.

19. Shukla D, Subhashis C, Sanjay S, Brahmeshwar M. Mouth dissolving tablets II: An overview of evaluation techniques. Sci Pharm 2009; 77:327-41.

20. Venkatarao M, Vidyadhara S, Sandeep D. Formulation and evaluation of Telmisartan solid dispersions using Entada scandens seed starch and Poloxamer-188 as superdisintegrants. Asian J Pharm Clin Res 2018;11:474-81.

21. Rubendra K, Dinesh KM, Dinesh KJ. Solid dispersion: A novel means of solubility enhancement. J Crit Rev 2016;3:1-8.

22. Emmanuel OO, Musiliu OA, Ekaete IA. Evaluation of callinectes chitosan as a superdisintegrant in metronidazole tablet. Int J Pharm Pharm Sci 2017;9:111-8. 